\title{
Estimation of genetic parameters for growth traits in a hatchery population of gilthead sea bream (Sparus aurata $\mathbf{L}$.)
}

\author{
Tiago Fernandes ${ }^{1,2}$ - Marine Herlin ${ }^{3}$ - María Dolores López Belluga ${ }^{4}$. \\ Guillermo Ballón $^{3}$ - Paulino Martinez ${ }^{5}$ Miguel A. Toro ${ }^{2}$. \\ Jesús Fernández
}

Received: 19 January 2016/Accepted: 4 August 2016

(C) Springer International Publishing Switzerland 2016

\begin{abstract}
The gilthead sea bream (Sparus aurata L.) is one of the most important marine fish species produced in southern European countries. Over the last two decades, microsatellites have become a powerful tool for DNA studies of fish populations, making it possible to establish existing genealogical relationships between individuals and to perform reliable estimates of genetic parameters. In the present study, a total of 7959 fish (494 breeders and 7465 fry) were genotyped using two rounds of multiplex reactions with four microsatellite markers each. Offspring were assigned based on the Mendelian exclusion principles, using FAP program. Genealogical information was successfully obtained for more than $83 \%$ of the progeny. Heritability estimates were close to 0.40 in all cases and for all considered traits. The lowest value was for the length at first age (350 $\pm 6 \mathrm{dph})$ and the highest for the length at the second age $(500 \pm 7 \mathrm{dph})$. The heritabilities for the first and the second weight were similar although somewhat higher for the second age, but not significant. The highest genetic correlations were found between weight and length at the same age and the lowest between weight and length at different ages. Based on the results of this study, it seems reasonable to expect that the implementation of a breeding program for improved growth in this population of gilthead sea bream will offer comparable
\end{abstract}

Tiago Fernandes

tiagofernandes.br@hotmail.com

1 Laboratório de Genética e Biotecnologia Aplicada a Aquicultura, Departamento de Engenharia de Pesca, Universidade Federal do Ceará, Av. Mister Hull 2977, Bloco 872, Fortaleza, Ceará 60356-000, Brazil

2 Departamento de Producción Animal, ETS Ingenieros Agrónomos, Universidad Politécnica de Madrid, 28040 Madrid, Spain

3 ABSA-Culmarex, 07007 Es CollD'enRabassa, Mallorca, Spain

4 Grupo Culmarex, 30880 Aguilas, Spain

5 Departamento de Xenética, Facultade de Veterinaria, Universidade de Santiago de Compostela, Santiago de Compostela 27002, Lugo, Spain

6 Departamento de Mejora Genética Animal, Instituto Nacional de Investigación y Tecnología Agraria y Alimentaria (INIA), 28040 Madrid, Spain 
performances to those achieved in other populations and species of great success in aquaculture around the world.

Keywords Heritability - Sparus aurata - Gilthead sea bream · Genetic correlation · Genealogy $\cdot$ Microsatellites · Parentage estimation

\section{Introduction}

The gilthead sea bream (Sparus aurata) is one of the most important marine fish species farmed in southern European countries. Most countries bordering the Mediterranean Sea produce sea bream and European sea bass (Dicentrarchus labrax) through intensive aquaculture. The total worldwide sea bream production in 2013 was of 173,062 tons. The main producers are Greece with around 71,000 tons (representing $41 \%$ of the total), Turkey with 37,000 tons (21.4\%) and Spain with 16,230 tons (9.4\%) (APROMAR 2015).

Over the last 4 years, the growth and consolidation of the gilthead sea bream industry have been accompanied by the stabilization of market prices but with important seasonal fluctuations that have, in turn, forced aquaculture companies to optimize their production and to plan further optimization strategies. In this sense, competitiveness among gilthead sea bream aquaculture producers has improved through minimizing production costs and/ or enhancing product value (Navarro et al. 2009).

The Mediterranean marine aquaculture industry shows an increasing interest in genetic improvement to maximize the efficiency of its production, especially since there has only been a short history of captive management of gilthead sea bream and published evidences of large potential gains achieved through selective breeding for certain traits of commercial interest such as growth. Selection response (i.e., the increase in the phenotypic mean of the population) in gilthead sea bream ranges between 5 and $10 \%$ per generation according to industrial reports (Knibb 2000). In recent breeding programs implemented in Greece, the estimated selection response for growth rate for the first cycle of selection reportedly reached 20-22\% (Rossi et al. 2006).

To increase the short- and long-term effectiveness of a selective breeding program in aquaculture, selection design should take into consideration both the maximization of the response to selection and the minimization of inbreeding. One difficulty lies in the productive characteristics of the species. With a mass spawning system, large variation in individual broodstock contributions to the progeny is expected. In commercial gilthead sea bream broodstock tanks, effective breeding population sizes are lower due to: (1) high male/female fecundity rates; (2) high variance in family size; and (3) fewer males than females contributing to each mass spawning event (male hierarchy). Under these circumstances, both the risk of inbreeding and the loss of genetic diversity become particularly high in cultured populations of this species (Brown et al. 2005b).

In order to establish a selection program and an appropriate management of inbreeding, fish progenies need to be traced back to their family groups. One major constraint for estimating genetic parameters in fish is the impossibility to tag hatchlings, and thus, families need to be reared separately until the physical tagging size is reached, if we want to trace back the genealogy. This limits the number of families that can be simultaneously evaluated and may bias family means by tank effects which, in turn, will bias (full-sib designs) or reduce the precision (half-sib designs) of the estimated genetic parameters (Gjedrem and Thodesen 2005). Consequently, most commercial programs are run in a mass spawning basis and families reared together. In this scenario, an alternative approach 
compatible with mass mating designs (which permits reliable estimations of genetic parameters) consists of using highly variable DNA markers, such as microsatellites for pedigree reconstruction. Over the last decade, a large number of polymorphic microsatellite loci have been developed in gilthead sea bream. Recent works have demonstrated the ability of markers to establish parentage in fish (reviewed in Martínez and Fernández 2008). Consequently, they provide a powerful tool for the evaluation of the breeding value of candidates to selection as well as for the management of genetic variability in breeding programs. The approach of resolving pedigrees using molecular markers in order to obtain estimates of genetic parameters in sea bream has been previously applied by several authors (Navarro et al. 2009; Antonello et al. 2009; Chavanne et al. 2014; García-Celdrán et al. 2015; Lee-Montero et al. 2015).

The main objective of this study was to estimate heritabilities and genetic correlations for growth traits in commercial/production conditions using a high amount of data. Also, we determined the distribution of the number of offspring per breeder when mass spawning is performed in gilthead sea bream, an important information to balance genetic contributions in a breeding program. We used the estimated parameters to create a productive long-term broodstock and to improve the production through a breeding program.

\section{Materials and methods}

\section{Biological samples: (individuals)}

The study consisted in analyzing the organization and potential performance of a gilthead sea bream broodstock population belonging to the commercial hatchery Aquicultura Balear SAU (Mallorca, Spain), where a genetic breeding program had been implemented since late 2007. The data presented here correspond to a complete cycle of selection, which was carried out from the middle of 2009 to the end of 2011.

The broodstock population was divided into five photoperiod groups, where each photoperiod consisted in two breeding tanks of $10 \mathrm{~m}^{3}$, accounting for a total of 10 tanks throughout this study.

The broodstock of this breeding program consisted of 494 individuals (202 males and 292 females), which were subjected to similar environmental conditions along all the spawning cycle (i.e., day length, water temperature, water salinity, sex ratio, stocking density and diet). The amount of breeding individuals arranged in each tank, corresponding to its photoperiod, are shown in Table 1.

Each breeding tank was made of approximately 20 males (average weight, $\mathrm{aw}=2.5 \mathrm{~kg}$ ) and 30 females $(\mathrm{aw}=2.7 \mathrm{~kg}$ ). However, notable differences existed between tanks and photoperiod cycles (see Table 1), mainly due to variations in annual sex reversal rates. Stocking densities were maintained within the range of $11-14 \mathrm{~kg} / \mathrm{m}^{3}$. Since sea bream is a protandrous hermaphrodite, there was a difference in age between both sexes: The females were on average 6 years old, while the males were 3 years old.

All breeding tanks were maintained under both light and water temperature regimes. Natural spawning was triggered by lowering the water temperature down to $17^{\circ} \mathrm{C}$ when reaching the photoperiod of 9:45 hours of light (HL)/14:15 hours of darkness (HD). Under these conditions, the spawning season lasted for about four and a half months with an average of $2.5 \mathrm{~kg}$ of viable eggs (approx. 3 millions) collected, on a daily basis, at the peak of the season (between 11:30 and 13:30 HL). In 2011, the average fecundity of the 
Aquacult Int

Table 1 Distribution of the number of individuals per tank and photoperiod

\begin{tabular}{lllccc}
\hline Photoperiod & Tank & Individuals & Male & Female & Fry \\
\hline $1^{\circ}$ & 1 & 38 & 10 & 28 & 1487 \\
& 2 & 35 & 12 & 23 & \\
$2^{\circ}$ & 3 & 42 & 20 & 22 & 1484 \\
& 4 & 48 & 19 & 29 & \\
$3^{\circ}$ & 5 & 52 & 25 & 27 & 1500 \\
& 6 & 49 & 23 & 26 & \\
$4^{\circ}$ & 7 & 53 & 23 & 30 & 1498 \\
& 8 & 53 & 22 & 31 & \\
$5^{\circ}$ & 9 & 57 & 18 & 39 & 1496 \\
& 10 & 67 & 30 & 37 & \\
& Total & 494 & 202 & 292 & 7465 \\
\hline
\end{tabular}

company Aquicultura Balear Sociedad Anónima (ABSA) sea bream broodstock reached $9.9 \mathrm{~kg}$ of eggs per female in each tank (i.e., $3.7 \mathrm{~kg}$ of eggs $/ \mathrm{kg}$ of female). Within each photoperiod cycle, fertilization rates were above $90 \%$, while the average hatching rate of commercial batches was equal to $86 \%$.

Sea bream broodstock was handed daily to satiation. Daily feeding rates varied according to a seasonal pattern which mainly depended on the sexual maturation stage of the brooders: from $0.6 \%$ of the tank biomass (outside the spawning season) down to $0.2 \%$ (during the spawning season). Fish were fed on a commercial pelleted diet supplemented, three times a week, during the course of the spawning season by frozen squid.

The fry groups used for the present genetic evaluation were issued from the commercial production of five juvenile batches (one per photoperiod cycle). Each batch originated from four consecutive days of egg collection from a single photoperiod cycle. The quantity of hatched larvae stocked in the hatchery was equally adjusted between both breeding tanks (A and B). On average, 8 million 1 day post-hatching (dph) sea bream larvae was stocked per batch with a $30 \%( \pm 5 \%)$ survival rate at $60 \mathrm{dph}$. At $130 \mathrm{dph}$, population was classified into three groups depending on the fish size; 1500 fry/batch were randomly chosen from the top grade size and transferred to the broodstock facilities. Fish were then commonly reared in a $20-\mathrm{m}^{3}$ tank until reaching $500 \mathrm{dph}$. During the on-growing stage, juveniles were daily fed to satiation on a commercial pelleted diet (both automatic feeders and hand feeding were used). The water temperature remained constant throughout the experiment: $20^{\circ} \mathrm{C}\left( \pm 1{ }^{\circ} \mathrm{C}\right)$.

All individuals included in this study (both the breeders and the juveniles) were physically tagged (at an average weight of $100 \mathrm{~g}$ ) through the injection of an internal transponder (pit-tag) placed below the dorsal fin, for later identification and evaluation at 350 and $500 \mathrm{dph}$. The number of breeders per tank and fry evaluated for each photoperiod cycle is also shown in Table 1.

\section{DNA extraction and microsatellite analysis}

DNA was obtained from a small caudal fin clip from adults and fry. DNA extraction was performed using the EZ96 ${ }^{\circledR}$ Tissue DNA Kit Omega Bio-tek. Eight microsatellites distributed in two multiplexes of four loci each were used for parentage allocation. The first multiplex was made up of SaI15, SaI19, SaGT32 and SaGT41a loci, while the second one 
of the PbMS16, PbMS2, SaI14 and SauG46INRA loci (Batargias et al. 1999; Stockley et al. 2000; Launey et al. 2003; Brown et al. 2005a). These loci were selected from the previous microsatellite tool developed by Castro et al. (2007; SAGT41a, PbMS16 and $\mathrm{PbMS} 2$ ) and from available information on genetic diversity and mapping for new markers (Franch et al. 2006; SaI15, SaI19, SaGT32 SaI14 and SauG46INRA). Linkage and genetic diversity information was obtained from the sea bream radiation hybrid map (Franch et al. 2006). Genotypes were obtained by capillary electrophoresis in an automatic sequencer ABI 3730xl DNA Analyzer (Applied Biosystems), and the categorization of the allelic series was made using the program GeneMapper v.4.0 (Applied Biosystems). Linkage and genetic diversity information was obtained from the sea bream radiation hybrid map (Sarropoulou et al. 2007). Both multiplex reactions were performed in $10 \mu$ total volume including $5 \mu \mathrm{l}$ of the GoTaq ${ }^{\circledR}$ Hot Start Colorless Master Mix kit, $1 \mu$ of the primer mix, $4 \mu \mathrm{l}$ of MQ water and $1 \mu \mathrm{l}$ of DNA. The PCR reaction included a first denaturation step at $95{ }^{\circ} \mathrm{C}$ for $2 \mathrm{~min}$, and 28 cycles of DNA denaturation at $94{ }^{\circ} \mathrm{C}$ for $30 \mathrm{~s}$, annealing for $1 \mathrm{~min}$ at $57{ }^{\circ} \mathrm{C}$ and extension for $1 \mathrm{~min}$ at $72{ }^{\circ} \mathrm{C}$; a final extension step was performed at $72{ }^{\circ} \mathrm{C}$ for $5 \mathrm{~min}$. The second multiplex was used only in cases where the results obtained with the first one were poor (i.e., low proportion of offspring assigned). Therefore, all the individuals not assigned in the first round were additionally analyzed using the second multiplex.

Assignation of progeny to parents was performed using the FAP (Family Assignment Program) software (Taggart 2007). The allocation was made for each photoperiod group, considering all possible candidate pair crosses in each of the two breeding tanks. No mismatches were allowed to determine exclusion. Only individuals assigned to a single couple of parents were kept for the analysis and became the candidates for selection. The theoretical probabilities of exclusion (Vandeputte 2012) were calculated from the allelic frequencies in each tanks and photoperiod and compared with the observed ones.

This pedigree reconstruction also allowed to determine the number of breeders actually contributing offspring to the next generation and the precise contributions of each of them. From this information, the effective population size $\left(N_{\mathrm{e}}\right)$ was estimated as $4 \mathrm{~N} /\left(2+V_{k}\right)$, where $N$ is the total number of available parents (males and females) and $V_{k}$ the variance of the number of offspring allocated to each of them. The expected $N_{\mathrm{e}}$ assuming random (Poisson distributed) contributions from all breeders was calculated as $\left(4 N_{\mathrm{s}} \times N_{d}\right)$ / $\left(N_{\mathrm{s}}+N_{\mathrm{d}}\right)$, being $N_{\mathrm{s}}$ and $N_{\mathrm{d}}$ the available number of sires and dams, respectively.

To explain differences in paternity assignment percentage between photoperiods, the relationship of the breeders in each tank was estimated using the molecular coancestry (through the allelic similarity method; Nejati-Javaremi et al. 1997) and inbreeding (i.e., observed homozygosity).

\section{Data analysis}

Two traits were measured, weight $(\mathrm{g})$ and standard length (measured from the tip of the mouth to the last vertebrae in centimeters), at two ages, approximately 350 and $500 \mathrm{dph}$, constituting the phenotypic data set. The estimates of heritabilities and correlations were obtained from a sample of 6205 individuals originating from the five photoperiod breeding groups (i.e., individuals successfully assigned to a single pair of parents with the FAP program). Since there was no previous information about pedigree, full-sibs, half-sibs and unrelated pairs were the only possible relationships for any couple of fish.

The components of the variance for all traits considered in this study were estimated for the four traits using a linear animal model: 


$$
y=X \beta+Z u+e
$$

where $y$ are the phenotypes for the trait, $\beta$ are fixed effects (photoperiod and tank), $u$ is the random genetic (additive) effect, and $e$ is the residual error. $X$ and $Z$ are the corresponding incidence matrices.

Three software packages (VCE, REMLf90 and TM) were used for the estimation. VCE (Kovac et al. 2002) and REMLf90 (Misztal et al. 2002) programs provide REML estimates of variance components. Contrarily, TM (Bayesian-based software, Legarra et al. 2008) uses MCMC and Gibbs sampling methods with flat priors for fixed effects and variance components and provides posterior distributions for the parameters of interest.

\section{Results}

\section{Parental assignment and data set}

At the end of the selection round (i.e., the five photoperiods of 1 year), a total of 494 broods $(202 \hat{\jmath}, 292$ + $)$ and 7465 fry were genotyped. Based on the allelic frequencies and the number of parents present in each tank, the theoretical assignment power ranged from 91 to $95 \%$. Genealogical allocation to a single couple, based on the molecular marker profiles, was possible for an important proportion of individuals $(83.12 \%)$ but lower than the expected value. In Table 2, the number of offspring assigned per photoperiod group and for each microsatellite multiplex reaction is presented.

In three of the five photoperiod groups (1, 3 and 4), the resolution power of the first multiplex was sufficient to successfully assign 3674 out of 4485 offspring (81.92\%) to a single pair of parents. In the two remaining photoperiods ( 2 and 5), only $62.08 \%$ (1850 fishes) were correctly assigned using the same multiplex. Therefore, the second multiplex was used on the remaining 1130 to improve assignment. This process allowed the assignment of an extra set of 678 individuals. All in all, it was possible to reconstruct the genealogy of 6205 offspring out of $7465(83.12 \%)$.

Table 2 Number of individuals assigned using multiplex 1 and multiplex 2 at each photoperiod

\begin{tabular}{|c|c|c|c|c|c|c|}
\hline \multirow[t]{2}{*}{ Photoperiod } & \multirow[t]{2}{*}{ Genotyped } & \multicolumn{2}{|c|}{1 Multiplex ${ }^{a}$} & \multicolumn{2}{|c|}{2 Multiplex ${ }^{\mathrm{b}}$} & \multirow[t]{2}{*}{ Total assignmen } \\
\hline & & ASIG. & $\mathrm{NO}$ & ASIG. & NO & \\
\hline $1^{\circ}$ & 1487 & 1202 & 285 & - & - & $1202(80.83 \%)$ \\
\hline $2^{\circ}$ & 1484 & 955 & 529 & 392 & 137 & 1347 (90.77 \%) \\
\hline $3^{\circ}$ & 1500 & 1295 & 205 & - & - & $1295(86.33 \%)$ \\
\hline $4^{\circ}$ & 1498 & 1177 & 321 & - & - & $1177(78.57 \%)$ \\
\hline $5^{\circ}$ & 1496 & 895 & 601 & 289 & 312 & $1184(79.14 \%)$ \\
\hline Total & 7465 & 5524 & 1941 & 681 & 449 & $6205(83.12 \%)$ \\
\hline
\end{tabular}

In parentheses the percentage of assignments

a Sal15 and Sal 19 (Brown et al. 2005a, b), Sagt32 and Sagt41a (Batargias et al. 1999)

b PbMS2 and PbMS16 (Stockley et al. 2000), Sal14 (Brown et al. 2005a, b) and SauG46INRA (Launey et al. 2003) 
Trying to determine the causes for the lower accuracy of the assignment in the two aforementioned photoperiods, the molecular coancestry and inbreeding coefficient in the breeders of each tank were calculated. Coancestry in tanks 3, 4 (photoperiod 2) and 9, 10 (photoperiod 5) was up to $15 \%$ higher than the average for the rest of tanks and inbreeding $40 \%$ higher. This fact may be behind the worse performance when reconstructing the families observed in those tanks.

Based on the reconstructed genealogy information, individual brood fish contributions to the studied progeny could be analyzed. The results are presented in Table 3 and Fig. 1. Our data showed that not all the breeders had progeny, thus reducing the effective population size of the stock. This situation was especially severe in some tanks and photoperiod groups with $<50 \%$ of males or females contributing to the studied progeny. Moreover, the number of offspring generated per breeder was also highly variable. The average contribution of individual male breeders was 44.0 offspring (ranging from 30.9 to 90.7 according to photoperiod groups; Fig. 1a). The highest variance in individual male contributions was observed for the first photoperiod group, whereas the lowest variation was registered for the photoperiod groups 4 and 5. The average contribution of individual female breeders was of 28.9 offspring (Fig. 1b) and was similar in all photoperiod groups except in the photoperiod 2 which showed higher values (37.4). There were also important differences among tanks (from 18.4 to 41.0) (Fig. 2). The photoperiod 2 also showed the highest variance of female contributions.

In the cases where the two multiplexes were applied (photoperiods 2 and 5), we could calculate the gain obtained by increasing the number of markers used in terms of the number of breeders with allocated offspring (Table 4).

It can be clearly seen that increasing the number of genotyped microsatellites barely increase the number of breeders with allocated progeny (in fact, dams are the same in the four tanks). Thus, the new allocated individuals (ranging from 60 to 318 depending on the photoperiod and tank) do not significantly increase the number of half-sib (HS) families since they are assigned to already detected parents. Accordingly, the variance of contributions is not reduced (except for tank 10) and, sometimes, even slightly increases with the consequence of rendering lower effective population sizes. $N_{\mathrm{e}}$ values obtained from the variance of the contributions moved from 21.94 to 22.51 , from 18.54 to 18.30 , from 16.84 to 16.81 and from 34.36 to 45.21 for tanks 3, 4, 9 and 10, respectively.

It is also remarkable that the increase in represented full-sib (FS) families when comparing assignation with 4 and 8 microsatellites is higher than the number of new HS families detected. This is another indication that the limited number of contributing breeders is not a consequence of the assignation process, but reflects the fact that not all parents are reproducing.

From all possible pairs among the 6205 fry which had their pedigree successfully reconstructed (i.e., $6205 \times 6205$ ) and which were later subjected to the genetic evaluations, $0.25 \%$ corresponded to full siblings, $2.03 \%$ shared either the father or the mother (half-sibs), and a total of $97.72 \%$ were unrelated individuals (no common parent).

\section{Statistical description of data}

The mean, standard deviation and coefficient of variation for weight and length measures at the two considered ages together with daily weight gain, daily length gain and the condition factor values are presented in Table 5. For weight and length measurements, the standard deviation was greater for the second measure due to the positive correlation between mean and variance typical for growth traits. Figure 3 shows the weight 


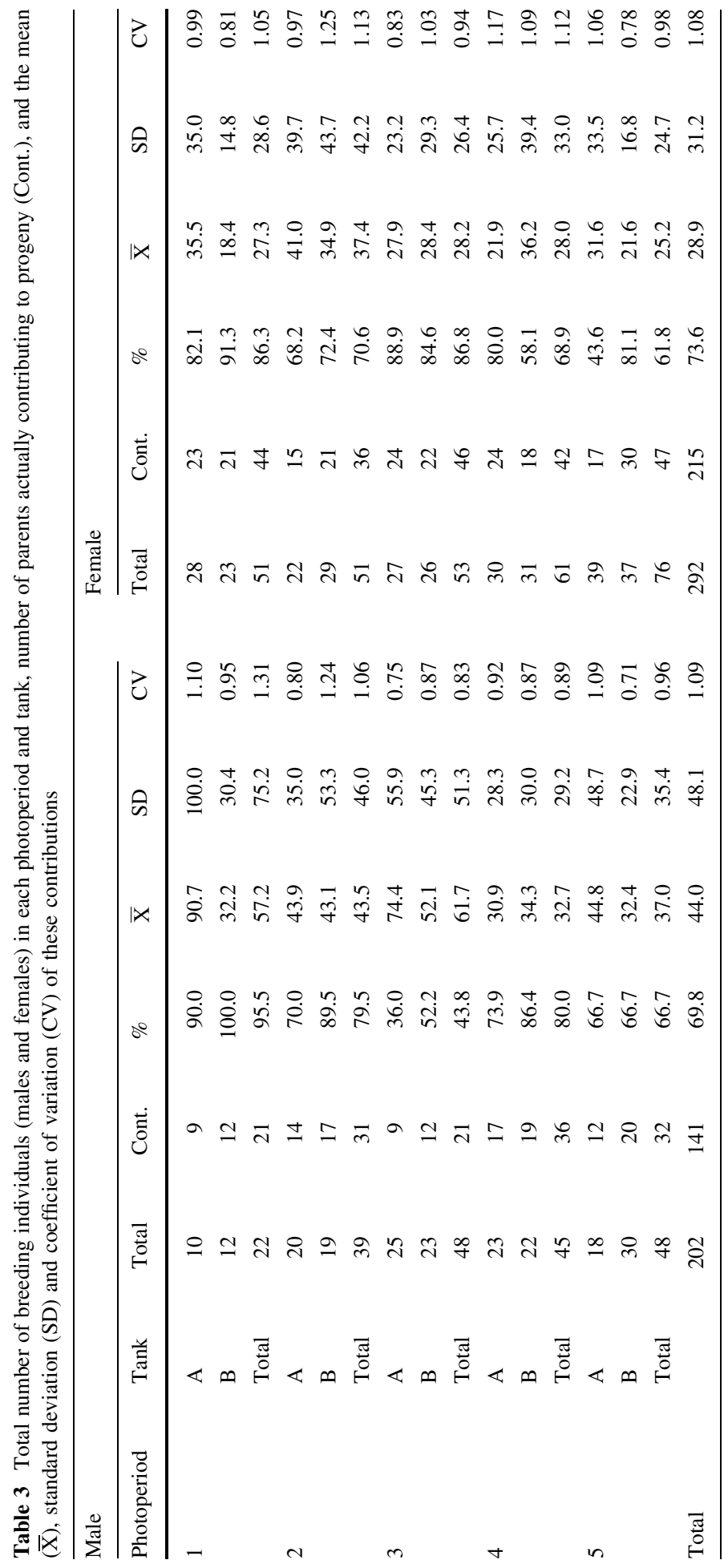



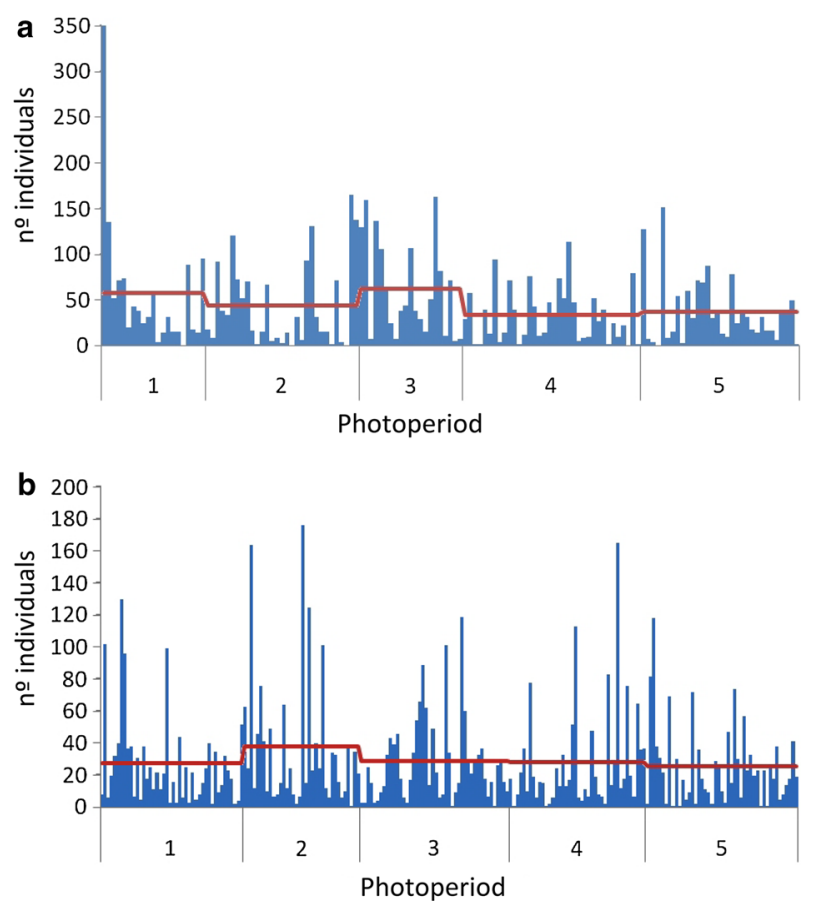

Fig. 1 a Contribution of the males. Line represents the average for each photoperiod. b Contribution of the females. Line represents the average for each photoperiod

Fig. 2 Number of individuals assigned to each tank generated in each photoperiod

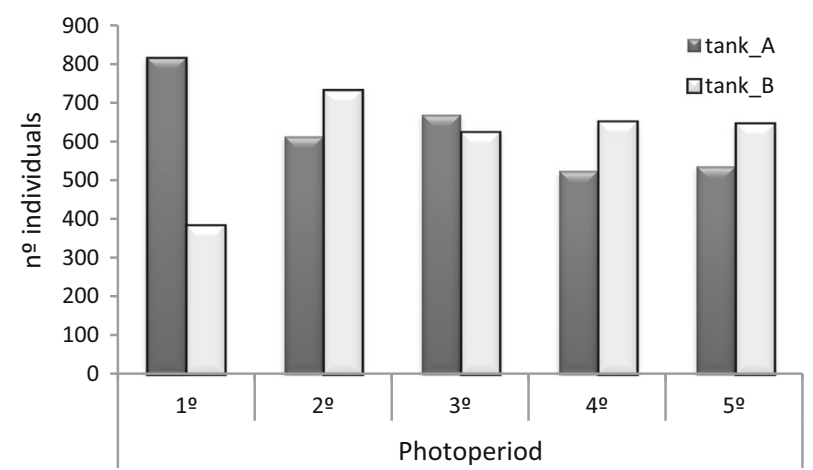

distribution obtained at both the first (A) and second (B) measurement for the five studied photoperiod groups. For the first measure, the standard deviation (and the coefficient of variation) for all studied variables was greater in photoperiod groups 1 and 2 since field data were collected over a 12-day period (photoperiod 1) and 19-day period (photoperiod 2 ), whereas in photoperiod groups 3, 4 and 5, field data were gathered within only 2 days of interval. For the second measure, close to harvest weight, the average phenotypic weight ranged from $385.6 \mathrm{~g}$ (photoperiod 3) to $421.2 \mathrm{~g}$ (photoperiod 5) which corresponded to average lengths of 24.3 and $24.7 \mathrm{~cm}$, respectively. As expected, the coefficients of 
Table 4 Number of sires and dams available and with allocated offspring, in the cases where 4 and 8 microsatellites have been used

\begin{tabular}{|c|c|c|c|c|c|c|c|}
\hline \multirow[t]{2}{*}{ Photoperiod } & \multirow[t]{2}{*}{ Tank } & \multirow[t]{2}{*}{ No. sires } & \multirow[t]{2}{*}{ No. dams } & \multicolumn{2}{|c|}{ Allocated sires } & \multicolumn{2}{|c|}{ Allocated dams } \\
\hline & & & & 4 micro & 8 micros & 4 micros & 8 micros \\
\hline \multirow[t]{2}{*}{2} & 3 & 19 & 23 & 14 & 14 & 15 & 15 \\
\hline & 4 & 19 & 30 & 13 & 17 & 21 & 21 \\
\hline \multirow[t]{2}{*}{5} & 9 & 18 & 39 & 12 & 12 & 17 & 17 \\
\hline & 10 & 30 & 37 & 17 & 20 & 30 & 30 \\
\hline
\end{tabular}

Table 5 Mean $(\overline{\mathrm{X}})$, standard deviation (SD) and coefficient of variation $(\mathrm{CV})$ of the measured traits

\begin{tabular}{|c|c|c|c|c|c|c|}
\hline \multirow[t]{2}{*}{ Photo } & \multicolumn{2}{|c|}{ Age (days) } & \multicolumn{2}{|c|}{ Weight (g) } & \multicolumn{2}{|c|}{ Length $(\mathrm{cm})$} \\
\hline & 1 & 2 & 1 & 2 & 1 & 2 \\
\hline \multicolumn{7}{|l|}{$\bar{X}$} \\
\hline 1 & 351.9 & 494.5 & 154.7 & 386.5 & 18.1 & 24.4 \\
\hline 2 & 339.8 & 497.6 & 132.6 & 414.6 & 16.9 & 24.5 \\
\hline 3 & 351.1 & 502.1 & 175.2 & 385.6 & 19.5 & 24.3 \\
\hline 4 & 344.1 & 506.5 & 145.6 & 387.9 & 18.1 & 25.1 \\
\hline 5 & 347.1 & 487.0 & 192.8 & 421.2 & 19.7 & 24.7 \\
\hline Average & 346.7 & 497.7 & 159.7 & 399.2 & 18.4 & 24.6 \\
\hline \multicolumn{7}{|l|}{ SD } \\
\hline 1 & 5.49 & 0.50 & 33.37 & 70.29 & 1.24 & 1.41 \\
\hline 2 & 7.29 & 2.35 & 28.65 & 69.23 & 1.13 & 1.27 \\
\hline 3 & 0.77 & 5.92 & 26.91 & 56.66 & 0.93 & 1.13 \\
\hline 4 & 0.80 & 0.50 & 21.45 & 54.42 & 0.81 & 1.04 \\
\hline 5 & 0.84 & 0.00 & 28.39 & 56.92 & 1.01 & 1.11 \\
\hline Average & 6.22 & 7.29 & 35.30 & 63.91 & 1.46 & 1.23 \\
\hline \multicolumn{7}{|l|}{$\mathrm{CV}$} \\
\hline 1 & 1.56 & 0.10 & 21.58 & 18.19 & 6.87 & 5.76 \\
\hline 2 & 2.15 & 0.47 & 21.60 & 16.70 & 6.70 & 5.18 \\
\hline 3 & 0.22 & 1.18 & 15.36 & 14.69 & 4.80 & 4.65 \\
\hline 4 & 0.23 & 0.10 & 14.73 & 14.03 & 4.49 & 4.16 \\
\hline 5 & 0.24 & 0.00 & 14.73 & 13.52 & 5.16 & 4.48 \\
\hline Average & 1.80 & 1.46 & 22.10 & 16.01 & 7.92 & 5.01 \\
\hline
\end{tabular}

variation were greater for weight than for length for both measures regardless of age $(22.10$ and 7.92 for age 1 , and 16.01 and 5.01 for age 2).

\section{Analysis}

\section{Fixed effects}

Table 6 displays the estimates of photoperiod effect in the five photoperiod groups obtained with the software VCE 6.0, which uses the variance components for estimation. Photoperiod 5 showed the highest values for the four traits (except for length at second 
Fig. 3 Distribution of the first $(A)$ and second $(B)$ weight measurement in each tank and photoperiod

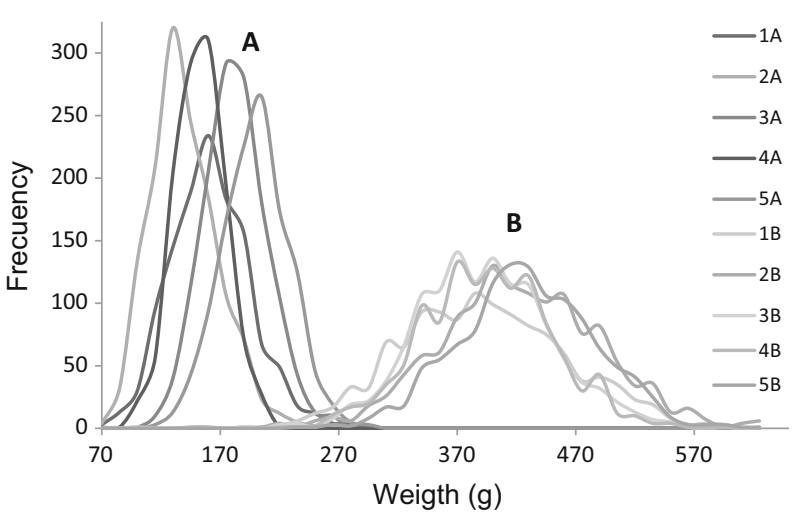

age). There is a good agreement between these estimates and the average of phenotypic values of the corresponding photoperiods although the differences are magnified.

\section{Heritability and correlations}

Genetic and phenotypic correlations among growth traits and their estimated heritabilities are shown in Table 7 for the VCE software. Values obtained from REMLf90 and TM were very similar to those by VCE even when they rely on different methodologies (VCE and REMLf90 maximum likelihood methodology and TM Bayesian approach), although there are some minor differences among them. For example, the VCE program provides the standard error of estimates, while the REMLf90 does not. On the other hand, the TM program is the only one which provides the complete posterior distributions of the parameters and their associated standard errors.

The heritability estimates obtained with TM were slightly higher, but in all cases close to 0.40 (standard errors about 0.03 ). The lowest value was for the length at first age and the highest value for the length at the second age. The heritabilities for the first and the second weight were similar, whereas the heritabilities for length differed more between the two ages (higher for the second age). However, all these differences were not significant.

The estimates of genetic and phenotypic correlations were also similar for all methods of estimation. The highest genetic correlations were between weight and length at the same age ( 0.89 for the first age and 0.91 for the second age) and the lowest between weight and length at different ages ( 0.77 between weight at the first age and length at the second age and 0.81 between length at first age and weight at second age). The phenotypic correlations

Table 6 Estimated effects of the photoperiod fixed factor for the different traits

\begin{tabular}{lcccc}
\hline Photoperiod & Weight $1(\mathrm{~g})$ & Length 1 $(\mathrm{cm})$ & Weight 2 $(\mathrm{g})$ & Length 2 $(\mathrm{cm})$ \\
\hline 1 & -43.33 & -1.84 & -45.67 & -0.50 \\
2 & -58.41 & -2.83 & -5.03 & -0.39 \\
3 & -17.70 & -0.37 & -30.52 & -0.41 \\
4 & -49.91 & -1.76 & -43.22 & 0.13 \\
5 & 0.00 & 0.00 & 0.00 & 0.00 \\
\hline
\end{tabular}


Table 7 Phenotypic correlations (below diagonal), genetic correlations \pm standard errors (above diagonal) and heritability \pm standard errors (diagonal) for growth traits

\begin{tabular}{lllll}
\hline & Weight 1 & Length 1 & Weight 2 & Length 2 \\
\hline Weight 1 & $0.39 \pm 0.03$ & $0.89 \pm 0.02$ & $0.86 \pm 0.02$ & $0.77 \pm 0.03$ \\
Length 1 & 0.84 & $0.37 \pm 0.03$ & $0.82 \pm 0.03$ & $0.88 \pm 0.02$ \\
Weight 2 & 0.75 & 0.66 & $0.41 \pm 0.03$ & $0.91 \pm 0.01$ \\
Length 2 & 0.66 & 0.67 & 0.78 & $0.42 \pm 0.03$ \\
\hline
\end{tabular}

followed the same pattern: maximum between weight and length at the same age ( 0.84 for the first age and 0.77 for the second age) and minimum between different traits at different ages ( 0.66 between weight at the first age and length at the second age and 0.65 between length at first age and weight at second age).

\section{Discussion and conclusions}

To achieve rapid genetic progress, selective breeding programs based on the genetic evaluations of individuals combining phenotypic and genealogical information are fairly common in livestock animals. However, in the aquaculture industry, this type of program is still rather new although rapidly expanding. For the implementation of a genetic breeding program, it is essential to properly evaluate, within the studied population, the genetic parameters of the trait(s) of interest. The objective of the present work was to estimate such parameters in a gilthead sea bream captive stock reared under industrial conditions. This type of studies have been already conducted in other populations of sea bream, but the present one used more fishes than any other and, thus, provides very low standard errors for the estimates. Moreover, we present detailed data about 10 mass spawning tanks which allows for the determination of the differences in the contributions of the breeders staying in the same tank under mass spawning.

The sea bream industry is primarily interested in selecting for traits which are common to most fish species under commercial culture and which include those determining production costs or affecting consumer preferences (Navarro et al. 2009; Chavanne et al. 2016). Despite the existing biological differences between species, most breeding programs for fish share the breeding objectives related to growth, the presence of deformities, meat quality and disease resistance.

Knibb et al. (1997) estimated heritabilities for growth traits in gilthead sea bream based on the data taken at slaughter weight after one generation of divergent selection (i.e., one line selected for increase in weight and the other selected for lower weight). Both lines were compared with a control line to avoid the problems of asymmetrical response to selection in opposite directions. The estimated values were of $0.51 \pm 0.13$ for the upward selected line and $0.29 \pm 0.04$ for the downward one. Navarro et al. (2009) estimated the heritability for growth characters at different ages, also under industrial conditions, finding values of 0.31 and 0.27 for weight and length at 330 days and 0.34 and 0.33 for length at 509 days. In our study, higher heritability values (around 0.40) were found and could be due to the different management conditions or the higher genetic variability of our population. In any case, the heritability of both studies shows that gilthead sea bream is a 
species with a significant additive genetic component for growth traits, an economic relevant fact for industry. Antonello et al. (2009) and Chavanne et al. (2014) also obtained estimates of heritability for growth in the same range ( 0.38 and 0.40 , respectively). This highlights the possibility of using these estimates to improve the productivity of the population, as already shown by Chavanne et al. (2014).

In a selective breeding program, not only genealogical information is important to carry out genetic evaluations on future breeder candidates, but also to ensure that inbreeding is minimized in order to palliate the loss of genetic variability. This can be implemented using the theory of the optimal contributions (Meuwissen 1997) which established how to obtain the highest gain with restricted inbreeding rate. In most fish species, both fecundation and embryonic development are external which makes difficult, as compared to mammals, to establish the degree of relationship among the progeny. In sea bream, an additional difficulty comes from the fact that broodstock changes sex throughout their life.

Even with mass spawning, some control on the rate of inbreeding can be also exerted by sorting the new breeders among photoperiods and tanks in such a way that they are allocated considering the degree of relatedness among individuals of the different tanks, and thus, the probability of inbred matings is reduced (Martínez and Fernández 2008).

The present study corroborates that, in the absence of pedigree information, microsatellite-based genetic is a valid tool to identify the families in a sea bream aquaculture breeding program even from a reduced panel of microsatellites. This approach makes unnecessary to grow separate families until fry are large enough to perform physical tagging and, additionally, suppresses environmental effects, making more accurate the estimates of genetic parameters.

Discrepancies between the expected (mean $93 \%$ ) and observed $(83 \%)$ percentage of correct assignments (i.e., single father and mother) may be due to the fact that theoretical expectations are calculated assuming large panmictic populations (in $\mathrm{H}-\mathrm{W}$ equilibrium) with the corresponding frequencies. As this assumption is not fulfilled, the power falls to the levels actually observed in the study. Comparisons between the expected levels of homozygosity (calculated from the coancestry coefficient) and the observed levels (inbreeding) show differences which reflects the deviation from the $\mathrm{H}-\mathrm{W}$ equilibrium of the breeder population (see values in the "Results" section).

It must be noticed that the assignment process was performed not allowing mismatches. Being less strict, it would have been possible to assign some extra offspring, but the number of uncertain paternities (i.e., several possible parents) would also increase, with the corresponding complications for the management of the breeding program. The advantage in aquaculture is that the huge number of evaluated candidates leads to low loss of genetic diversity due to selective pressure, even if some individuals are discarded, not compromising seriously the expected genetic response unless culled candidates are those with higher breeding values.

Nevertheless, using the four most informative microsatellites, an enough parental assignment ( $83 \%$ of the cases) was obtained in three out of the five photoperiods. The other two photoperiod groups required the application of a second microsatellite panel to achieve similar assignment figures likely due to the existence of a higher relationship among some breeders (see results presented before), thus complicating parental allocation.

It must be highlighted that, although more individuals were assigned, no significant changes in the number of breeders were achieved and, accordingly, neither in the effective population size. The values of the $N_{\mathrm{e}}$ which determines the amount of genetic diversity transmitted to the next generation and, therefore, affects the increase in inbreeding (with its deleterious consequences) and compromises the results of the breeding program. 
The above comparisons suggest that the reduction in the number of potential breeders and the effective number of parents is not due to the parental allocation process, but it seems actually a problem of the participation of breeders in reproduction; not all the available parents in each tank yield offspring. This leads to a large reduction in the effective population size from that expected if all parents would have the same contribution. If a direct control of the mating process was possible and the contributions from each parent were equalized, the effective population sizes could rise to 83, 94, 99 and 122 in each tank, respectively. This should be taken into account when planning a breeding program and deciding whether mass spawning or directed matings are to be implemented.

Another factor that could affect the observed outcome is the implicit selection that is applied during the growing period, as the genotyped offspring (i.e., candidates to final selection) are taken from the group of bigger fishes after a grading process. Therefore, offspring of some parents (families) may have been classified in lower categories and not genotyped. This aspect would deserve further investigation to find out whether the initial selection process is dangerously reducing the genetic diversity of the stock.

The outcomes of this study are in agreement with those from other authors, who, in the absence of pedigree information, demonstrated that microsatellite-based genetic tools are very useful for paternity inference to identify families in sea bream aquaculture breeding programs (Castro et al. 2007; Navarro et al. 2008; Porta et al. 2010; Borrell et al. 2011; Chavanne et al. 2014). In fact, some of these authors obtained higher percentages of parental assignment close to $100 \%$ (see for example Lee-Montero et al. 2015). Also, selection of markers through mapping information is essential to avoid linkage between markers that could reduce their assignment power (Jones et al. 1998). In our study, markers were selected using genetic diversity estimates and map position from sea bream map (Franch et al. 2006), thus conforming a new resolution tool for parentage evaluation in this species. Using the four highest powerful microsatellites, parental assignment was above $80 \%$ in three out of five photoperiods, and a second multiplex was necessary in the two remaining ones to reach a similar figure or to reach $90 \%$ assignment. These values, although reasonable to support a genetic breeding program, deviates significantly from expected values likely due to kinship among breeders, thus complicating parental allocation. In this sense, relatedness estimation or pedigree reconstruction of the broodstock from these microsatellites could aid to its reorganization in photoperiods and tanks according to minimum parentage values (Martínez and Fernández 2008).

In our study, weight and length at both ages (350 and 500 days approximately) showed heritability values close to 0.40 (standard errors about 0.03 ). These values are higher than those found by Navarro et al. (2009) probably due to the more uniform conditions of management. Besides this, the genetic correlation between both traits is high (being as high as 0.91 between weight and length at the second age), and thus, any of them could be used as a selection criterion whatever the trait chosen as the objective of selection. Navarro et al. (2009) suggested that length could be a preferable trait for selection because it is easier to measure. However, we choose estimated the heritability of weight close to commercial weight, because it is the condition which renders higher economic benefits (personal communication of the company) as sea bream is mostly sold by weight (i.e., prices proportional to weight not to length). On the other hand, the genetic correlation found between the same traits measured at different ages suggests that, in this case, it would be possible to select future broodstock based on the first measure (at $350 \mathrm{dph}$ ) which might be of economic relevance for the hatchery. However, we consider that it is still preferable to select fish based on the information at the second age (closer to commercial weight). 
In summary, given the present results, it seems reasonable to assume that the implementation of a breeding program for improved growth in gilthead sea bream will translate into a genetic progress similar to the one already achieved in other species such as Atlantic salmon (Gjerde 1986; O’Flynn et al. 1999) or the Pacific salmon (Neira et al. 2006).

\section{References}

Antonello J, Massault C, Franch R, Haley C, Pellizzari C, Bovo G, Patarnello T, Koning D, Bargelloni L (2009) Estimates of heritability and genetic correlation for body length and resistance to fish pasteurellosis in the gilthead sea bream (Sparus aurata L.). Aquaculture 298:29-35

APROMAR (2015) La acuicultura en España. (https://drive.google.com/file/d/0B4_4E-v9oqL_ WUgtUzNrdE1MSzQ/view)

Batargias C, Dermitzakis E, Magoulas A, Zouros E (1999) Characterization of six polymorphic microsatellite markers in gilthead sea bream, Sparus aurata. Mol Ecol 8:897-898

Borrell Y, Gallego V, García-Fernández C, Mazzeo I, Pérez L, Asturiano JF, Carleos CE, Vázquez E, Sánchez JA, Blanco G (2011) Assessment of parental contributions to fast- and slow-growing progenies in the sea bream Sparus aurata L. using a new multiplex PCR. Aquaculture 314:58-65

Brown RC, Tsalavouta M, Terzoglou V, Magoulas A, McAndrew BJ (2005a) Additional microsatellites for Sparus aurata and cross-species amplification within the Sparidae family. Mol Ecol 5:605-607

Brown RC, Woolliams JA, McAdrew BJ (2005b) Factors influencing effective population size in commercial populations of gilthead sea bream, Sparus aurata. Aquaculture 247:219-225

Castro J, Pino A, Hermida M, Bouza C, Chavarrías D, Merino P, Sánchez L, Martínez P (2007) A microsatellite marker tool for parentage assessment in gilthead sea bream (Sparus aurata). Aquaculture 272(Supplement 1):210-216

Chavanne H, Parati K, Cambuli C, Capoferri R, Jiménez CA, Galli A (2014) Microsatellites markers to depict the reproductive and genetic patterns of farmed gilthead sea bream (Sparus aurata): illustration by a case study on mass spawning. Aquacult Res. doi:10.1111/are.12013

Chavanne H, Janssen K, Hofherr J, Aquatrace Consortium, Contini F, Haffray P, Komen H, Nielsen EE, Bargelloni L (2016) A comprehensive survey on selective breeding programs and seed market in the European aquaculture fish industry. Int Aquacult. doi:10.1007/s10499-016-9985-0

Franch R, Louro B, Tsalavouta M, Chatziplis D, Tsigenopoulos CS, Sarropoulou E, Antonello J, Magoulas A, Patarnello T, Power DM, Kotoulas G, Bargelloni L (2006) A genetic linkage map of the hermaphrodite teleost fish Sparus aurata L. Genetics 174:851-861

García-Celdrán M, Ramis G, Manchado M, Estévez A, Afonso JM, María-Dolores E, Peñalver J, Armero E (2015) Estimates of heritabilities and genetic correlations of growth and external skeletal deformities at different ages in a reared gilthead sea bream (Sparus aurata L.) population sourced from three broodstocks along the Spanish coasts. Aquaculture 445:33-41

Gjedrem T, Thodesen J (2005) Selection. In: Gjedrem T (ed) Selection and breeding programs in aquaculture. Springer, Berlin, pp 89-111

Gjerde B (1986) Growth and reproduction in fish and shellfish. Aquaculture 57:37-55

Jones AG, Kvarnemo C, Moore GI, Simmons LW, Avise JC (1998) Microsatellite evidence for monogamy and sex-biased recombination in the Western Australian seahorse, Hippocampus angustus. Mol Ecol 7:1497-1505

Knibb W (2000) Genetic improvement of marine fish-Which method for the industry? Aquacult Int $31: 11-23$

Knibb W, Gorshkova G, Gorshkov S (1997) Selection for growth in the gilthead sea bream, Sparus aurata L. Isr J Aquacult Bamidgeh 49:57-66

Kovac M, Groeneveld E, García-Cortés LA (2002) VCE-5: a package for the optimization of dispersion parameters. In: Proceedings of the 7th world congress of genetics applied to livestock production, Montpellier, France, 20-23 Aug 2002

Launey S, Krieg F, Haffray P, Bruant JS, Vanniers A, Guyomard R (2003) Twelve new microsatellite markers for gilthead sea bream (Sparus aurata): characterization, polymorphism and linkage. Mol Ecol 3:457-459

Lee-Montero I, Navarro A, Negrín-Báez D, Zamorano MJ, Borrell Pichs YJ, Berbel C, Sánchez JA, GarcíaCeldran M, Manchado M, Estévez A, Armero E, Afonso JM (2015) Genetic parameters and genotypeenvironment interactions for skeleton deformities and growth traits at different ages on gilthead sea bream (Sparus aurata L.) in four Spanish regions. Anim Genet 46(2):164-174 
Legarra A, Varona L, de Maturana EL, (2008) Program TM. http://snp.toulouse.inra.fr/ alegarra

Martínez P, Fernández J (2008) Estimating parentage relationships using molecular markers in aquaculture. In: Schwartz SH (ed) Aquaculture research trends. Nova Science Publishers, New York, pp 59-112

Meuwissen THE (1997) Maximizing the response of selection with predefined rate of inbreeding. J Anim Sci 75:934-940

Misztal I, Tsuruta S, Strabel T, Auvray B, Druet T, Lee DH (2002) BLUPF90 Andre lated programs (BGF90). In: Proceedings of the 7th world congress on genetics applied to livestock production, Montpellier, France, 20-23 Aug 2002

Navarro A, Badilla R, Zamorano MJ, Pasamontes V, Hildebrandt S, Sánchez JJ, Afonso JM (2008) Development of two new microsatellite multiplex PCRs for three sparid species: gilthead sea bream (Sparus aurata L.), red porgy (Pagrus pagrus L.) and redbanded sea bream (P. auriga, Valenciennes, 1843 ) and their application to paternity studies. Aquaculture 285:30-37

Navarro A, Zamorano MJ, Hildebrandt S, Ginés R, Aguilera C, Afonso JM (2009) Estimates of heritabilities and genetic correlations for growth and carcass traits in gilthead sea bream (Sparus aurata L.), under industrial conditions. Aquaculture 289:225-230

Neira R, Días NF, Gall GAE, Gallardo JA, Lhorente AC, Manterola R (2006) Genetic improvement in coho salmon (Oncorhynchus kisutch). I: selection response and inbreeding depression on harvest weight. Aquaculture 257:9-17

Nejati-Javaremi A, Smith C, Gibson JP (1997) Effect of total allelic relationship on accuracy of evaluation and response to selection. J Anim Sci 75:1738-1745

O'Flynn FM, Bailey JK, Friars GW (1999) Responses to two generations of index selection in Atlantic salmon (Salmo salar). Aquaculture 173:143-147

Porta J, Porta JM, Bejar J, Alvarez MD (2010) Development of a microsatellite multiplex genotyping tool for the fish Gilthead sea bream (Sparus aurata): applicability in population genetics and pedigree analysis. Aquacult Res 41:1514-1522

Rossi AR, Perrone E, Sola L (2006) Genetic structure of gilthead sea bream Sparus aurata, in the Central Mediterranean Sea. Cent Eur J Biol 1:636-647

Sarropoulou E, Franch R, Louro B, Power DM, Bargelloni L, Magoulas A, Senger F, Tsalavouta M, Patarnello T, Galibert F, Kotoulas G, Geisler R (2007) A gene-based radiation hybrid map of the gilthead sea bream Sparus aurata refines and exploits conserved synteny with Tetraodon nigroviridis. BMC Genom 8:44

Stockley BM, Rogers AD, Iyengar A, Menezes G, Santos R, Long A (2000) Ten microsatellite loci isolated and developed for the black spot sea bream, Pagellus bogaraveo (Brunnich, 1768). Mol Ecol 9:999-1000

Taggart JB (2007) FAP: an exclusion-based parental assignment program with enhanced predictive functions. Mol Ecol 7:412-415

Vandeputte M (2012) An accurate formula to calculate exclusion power of marker sets in parentage assignment. Genet Sel Evolut 44:36. doi:10.1186/1297-9686-44-36 